\title{
КОНКУРЕНТНЫЕ ПРЕИМУЩЕСТВА СФЕРЫ ТУРИЗМА НАЦИОНАЛЬНОЙ ЭКОНОМИКИ В УСЛОВИЯХ ЭКОНОМИЧЕСКОЙ ИНТЕГРАЦИИ
}

\author{
(C) 2020 Уржумцева Татьяна Борисовна \\ Научно-образовательный центр исследования социально-экономических проблем стран АТР, \\ руководитель центра \\ Санкт-Петербургский государственный экономический университет, Россия, Санкт-Петербург
}

В статье рассматриваются особенности понятий «конкурентоспособность отрасли» и «конкурентные преимущества» применительно к туристской индустрии; обосновывается необходимость выделения применительно к туристской индустрии уровня интеграционных объединений; приводится система конкурентных преимуществ туристской отрасли, включающая в себя конкурентные преимущества на уровне интеграционных объединений; дается авторское определение понятия «конкурентные преимущества индустрии туризма национальной экономики (страны) в туризме».

Ключевые слова: конкурентоспособность в туризме в условиях интеграции, конкурентное преимущество туризма страны, потребительская ценность.

В условиях глобализации современного мира национальные экономики отдельных государств начинают приобретать всё более открытый характер. Практически на всех рынках мира происходит ужесточение конкуренции. Вместе с тем конкуренция ассоциируется с развивающейся экономикой, так как стимулирует развитие производства, настраивает предприятия на максимальное удовлетворение потребностей рынка. Чем более открытая экономика той или иной страны, тем выше уровень конкуренции, тем актуальнее для экономики становится конкурентоспособность.

В настоящее время понятие «конкурентоспособность отрасли» авторы рассматривают с точки зрения неоклассического и институционального подходов. Первый подход определяет конкурентоспособность отрасли как совокупную способность ее предприятий проектировать, изготавливать и реализовывать товары данной отрасли, которые по ценовым и качественным характеристикам более привлекательны для потребителей, чем товары аналогичных зарубежных отраслей-конкурентов, обеспечивая при этом устойчиво высокие темпы экономического роста отрасли.

Сторонники институционального подхода [см., например, 2, с. 86] рассматривают сущность и содержание данной экономической категории не только через призму отдельных производителей, а и их внешней инфраструктуры. При этом конкурентоспособность отрасли следует определять, как наличие конкурентоспособных предприятий, формирующих отрасль, с одной стороны, и уровень межфирменных связей, обеспечиваемый различными отраслевыми институтами.

Данный подход, по нашему мнению, является актуальным для индустрии туризма, которая представляет собой многоотраслевой комплекс, объединяющий разнообразные по технологии производства и предоставления услуги (товары, работы) предприятия, относящиеся к различным видам экономической деятельности и, соответственно, отраслям национальной экономики [4, с. 40].

Представляется, что на современном этапе развития конкурентоспособность туризма складывается на шести уровнях, приведённых на рис. 1. На каждом уровне формируются свои условия конкурентной борьбы, своя субъектность, свои цели и свои временные горизонты и, соответственно, конкурентные преимущества.

Так как туристская индустрия, как и любая другая отрасль национальной экономики, представляет собой ее мезоуровень, то она аккумулирует преимущества как микро-, так и макро- уровня, что приводит к получению синергетического эффекта [2, с. 87]. Однако в условиях формирования и развития интеграционных объединений стран на туризм как отрасль национальной экономики начинают оказывать влияние и конкурентные преимущества, скалывающиеся на сверхмакроуровне. При этом, на макроуровне - стране (национальной экономике) - создаются условия конкуренто- 


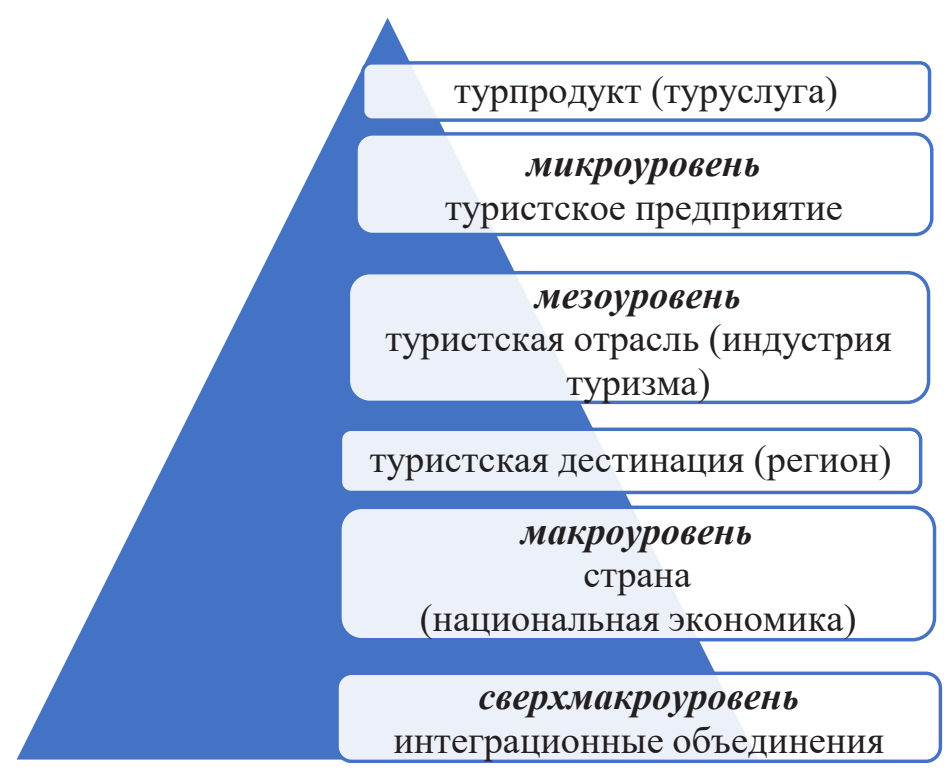

Puc. 1. Вертикальная структура конкурентоспособности в туризме

способности индустрии туризма, а на сверхмакроуровне - уровне интеграционных объединений - предпосылки конкурентоспособности страны как туристской дестинации и, соответственно, её турпродукта и туристских предприятий.

Конкурентоспособность отрасли определяется наличием у нее конкурентных преимуществ. Отрасль обладает конкурентным преимуществом в том случае, если данное (определенное) свойство в ней выражено в большей мере, чем у конкурирующих отраслей (аналогичных отраслей другой страны или других отраслей региональной экономики). Важность того или иного вида конкурентного преимущества отрасли зависит от силы его влияния на выбор потребителями услуг или товаров конкретной отрасли и получения предприятиями данной отрасли прибыли более высокой, чем в других отраслях.

В отечественной и зарубежной научной литературе существуют различные подходы к определению сущности понятия «конкурентное преимущество».

Впервые в экономической науке преимущества, определяющие конкурентоспособность, были рассмотрены меркантилистами, которые относили к ним дешевую рабочую силу, сырье и протекционистские меры со стороны государства. А.Смит и Д. Рикардо в теории абсолютных и относительных (сравнительных) конкурентных преимуществ указывали, что страна специ- ализируется на производстве тех товаров и услуг, изготовление которых получается экономичнее, а товары и услуги, производство которых не эффективно, импортирует из других стран [7].

В классической экономической литературе понятие конкурентного преимущества раскрыто Ж.-Ж. Ламбеном, который дает следующее определение конкурентного преимущества: «это те характеристики, свойства товара или марки, которые создают для фирмы определенное превосходство над своими прямыми конкурентами» [5]. Эти характеристики (атрибуты) могут быть самыми различными и относиться как к самому товару (базовой услуге), так и к дополнительным услугам, сопровождающим базовую, к формам производства, сбыта или продаж, специфичным для фирмы или товара. Указанное превосходство является относительным, определяемым по сравнению с конкурентом, занимающим наилучшую позицию на рынке или в сегменте рынка.

А.Алчинян, Т.Эггертсон и Г.Демсец в середине XX-го века в своих работах считали конкурентными преимуществами уникальные свойства, которые имеются у объекта по сравнению с другими конкурентами [8].

В начале XXI-го века взгляды ученыхэкономистов на сущность понятия «конкурентное преимущество» немного изменились. Например, Х. Траболт считал основным конкурентным преимуществом знания. Впоследствии, 
дополняя Х.Траболта, Д.Мур указывал на то, что эти знания должны все время развиваться. А.Бранденбургер предполагал, что конкурентные преимущества можно определить степенью соконкуренции [8].

Азоев Г.Л., А.П.Челенков считают, что «конкурентное преимущество - это концентрированное проявление превосходства над конкурентами в экономической, технической, организационной сферах деятельности предприятия, которые можно измерить экономическими показателями (дополнительная прибыль, более высокая рентабельность, рыночная доля, объём продаж)» [1, с. 87].

А. Ойхер в 2008 г. характеризовал конкурентные преимущества как способность предприятий (отраслей), ведущих конкурентную борьбу между собой, обеспечить лучшие условия для приобретения различных ресурсов и их эффективное использование [8].

Р.А.Фатхудинов определяет конкурентное преимущество как конкретный компонент (фактор) внешней и внутренней среды субъекта, по которому он превосходит конкурентов [см., например, 9].

В конце XX в. глобализация мировой экономики, развитие национальных рынков развитых стран, усиление интеграционных процессов вызвали необходимость к появлению новых научных исследований по выявлению конкурентных преимуществ стран и компаний, завоеванию лидирующих позиций на мировом рынке, отраслевом лидировании (М.Портер), стратегии завоевания «рынков будущего» (К.Прахалад, Г.Хамел), сочетания конкуренции и сотрудни- чества (Дж. Мур, А.Брандербургер, Б. Дж.Нейбафф). Например, в туризме в начале 2000 гг. в виртуальном пространстве - Интернете - даже появилась новая модель электронного бизнеса co-cooperation (конкуренция-кооперация) в гостиничном бизнесе.

Выявление иерархии конкурентных преимуществ является достаточно сложной методологической проблемой, в том числе и применительно к туризму. Именно сочетание конкурентных преимуществ на различных иерархических уровнях, приведённых на рис. 1 , дает возможность оценить конкурентоспособность туризма страны интегрально, т.е. комплексно.

По нашему мнению, конкурентные преимущества индустрии туризма страны зависят от того, как и какие конкурентные преимущества формируются на всех иерархических уровнях (рис. 2). Именно этот факт по мнению Н.С.Морозовой является важнейшей особенностью конкурентных преимуществ в туризме является их проявление на макро-, мезо- и микроуровнях и тесная связь между ними [6]. Представляется, что сегодня в результате формирования и развития различных политико-экономических союзов государств необходимо рассматривать ещё и сверхмакроуровень (глобальный) конкурентных преимуществ. Именно формирование и развитие конкурентных преимуществ на всех иерархических уровнях конкурентной среды позволяет получить синергетический эффект конкурентоспособности индустрии туризма страны.

К сожалению, сегодня в отечественной научной литературе существует не так много определений понятия «конкурентные преимущества

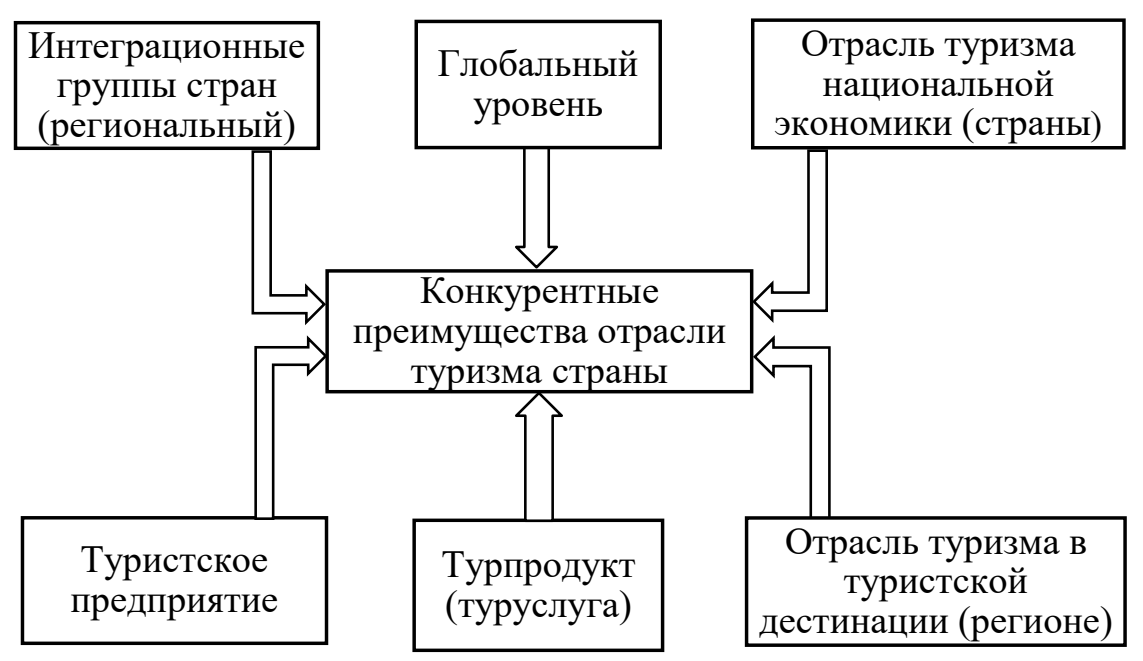

Puc. 2. Система конкурентных преимуществ туристской отрасли 
в туризме». Поэтому представляется необходимым уточнить это понятие с учётом современных тенденций в сфере туризма и развития интеграционных процессов.

Н.С.Морозова определяет конкурентные преимущества в туризме как способность «обладания определенными возможностями, позволяющими противостоять конкурентам, превосходстве над конкурентами по какому-либо параметру (фактору) в рассматриваемый период времени» [6, с. 45]. При этом основополагающим источником конкурентных преимуществ в туризме выступает принцип редкости (ограниченности) ресурсов, в том числе - туристских. В то же время факт наличия различного вида туристских ресурсов (природных, антропогенных, природно-антропогенных) еще не является конкурентным преимуществом. Например, огромное количество туристских ресурсов в России обычно рассматривается как потенциальная возможность развития туризма. Однако, проблема заключается в том, что туристские ресурсы используются в местах их существования - туристских дестинациях. То есть, туристов необходимо доставить в эту дестинацию, разместить, накормить и т.д. для чего требуется наличие соответствующей инфраструктуры. Поэтому, существует мнение, что превращение редкого туристского ресурса в конкурентное преимущество может быть обеспечено только при условии наличия необходимой инфраструктуры [6, с.45].

В то же время как показывает практика наличие вышеперечисленных конкурентных преимуществ в туризме является необходимым условием, но ещё не достаточным для обеспечения высокого уровня конкурентоспособности страны на мировом туристском рынке. По нашему мнению, необходимо ещё рассматривать такую составляющую конкурентных преимуществ в туризме как способность (потенциальную возможность) их реализовать в конкретное туристское предложение, т.е. в турпродукт, с целью повышения конкурентоспособности индустрии туризма страны на основе удовлетворения разнообразных потребностей туристов.

Применительно к туризму нам представляется актуальным научный подход, рассматривающий конкурентное преимущество объекта в качестве какой-либо эксклюзивной ценности, которой обладает данный объект, и которая дает ему превосходство перед конкурентами.

Например, по мнению Р.А.Фатхутдинова ценность - это нечто особенное, то, чем объект владеет (содержит в себе), стремится сохранить либо иметь в будущем.

Туристы в процессе всех этапов своего путешествия получают впечатления, которые обладают полезностью, потребительской ценностью и, в конечном счёте, определённой стоимостью. Взаимодействуя в процессе предоставления туристу различных видов услуг, каждое предприятие сферы туризма вносит свой «вклад» в создание совокупного впечатления и тем самым приращивает стоимость туристского продукта. Создание новой потребительской ценности впечатлений - происходит в тесном взаимодействии предприятий туризма и непосредственно самого туриста. По мнению некоторых учёных сегодня турпродукт - это не то, что предлагает туроператор, а то, что создаёт сам потребитель [4, с.36]. При этом в создании комплексного туристского продукта задействованы предприятия различных отраслей экономики страны (региона). В результате потребитель получает наилучший потребительский опыт, а предприятий сферы туризма - конкурентные преимущества. Именно потому для предприятий сферы туризма является весьма актуальным использование инструментов маркетинга взаимоотношений.

Представляется, что конкурентное преимущество индустрии туризма национальной экономики (страны) - это совокупность различного вида ценностей (материальных, финансовых, трудовых, природных, туристских и т.д.) на всех уровнях управления, которые позволяют субъекту (интеграционным группировкам стран, стране, туристской отрасли, предприятию, турпродукту) достичь превосходства на туристском рынке над своими конкурентами, а также способностей и возможностей (потенциальной энергии) их использовать в целях повышения конкурентоспособности на мировом туристском рынке.

По нашему мнению, именно «способности и возможности» представляют в современных условиях высокой конкуренции ту важнейшую основу, которая позволяет на всех уровнях управления туризмом (в том числе национальном уровне) обеспечивать определённый уровень конкурентоспособности. Их важнейшее «призвание»- использовать имеющиеся в распоряжении страны как туристской дестинации разнообразные виды ресурсов, в том числе и туристские, и посредством непрерывного воспроизводства их новых комбинаций (как в реальном, так и виртуальном пространстве) обеспечивать 
развитие уже существующих и появление новых конкурентных преимуществ.

Дж.Гилфорд выделил 16 интеллектуальных гипотетических способностей, характеризующих креативность [3]. Впоследствии он их объединил в понятие «дивергентное мышление», отражающее познавательную строну креативности. К некоторым факторам данного вида мышлению он отнес:

- беглость - количество идей, возникающих в единицу времени;

- гибкость - способность переключаться с одной идеи на другую;

- оригинальность мышления - способность продуцировать идеи, отличающиеся от общепринятых;

- любознательность - повышенная чувствительность к проблемам, не вызывающим интереса у других;

- иррелевантность - логическая независимость реакций от стимулов.

В условиях постиндустриального этапа развития человечества труд приобретает универсальные составляющие: он становится креативным (творческим) [10]. Поэтому повышение конкурентоспособности туристской отрасли отдельной страны, а также интеграционных объединений стран, непосредственно зависит от творческого подхода к управлению туризмом.

На уровне страны - ещё с 90-х годов ХХ в. Дания представляла себя как туристскую дестинацию на мировом туристском рынке посредством рекламных буклетов для разных сегментов рынка по-разному: в оформлении туристских буклетов использовались разные фотографии в зависимости от того, на какую страну данный буклет ориентирован. Например, если это был буклет для немецких туристов, то это были фотографии, отражающие семейный отдых. А для испанских туристов использовали фотографии, показывающие фееричный, активный отдых, ночные развлекательные программы и т.д.

В условиях цифровой экономики конкурентным преимуществом страны в сфере туризма выступает также разнообразие в использовании информационных технологий. Причём не только в предоставлении широких возможностей в бронировании туристских услуг на сайтах туристских дестинаций, а и возможность виртуальной прогулки по её достопримечательностям.
Например, Национальная галерея в Лондоне первая предоставила возможность виртуального «путешествия» по его экспозиции в режиме on-line.

Турция в целях увеличения туристского потока из Китая в 2018 г. распространила в местных соцсетях клип песни «Dai ni qu luxing» («Я возьму тебя в путешествие») в исполнении популярного певца Сяо Чжана, обещающего своей подруге «романтическую Турцию» на фоне сцены полета воздушных шаров над Каппадокией. Как рассказывали китайские туристы, клип оказал большое влияние на популярность поездок в Турцию. «Мне бы хотелось увидеть Каппадокию на борту воздушного шара»,- заявляют они, ссылаясь на официальный видеоролик песни*. В результате по данным государственного агентства Anadolu, число китайских туристов, посетивших Турцию, достигло 191000 человек в первой половине 2018 года, что на 91\% выше, чем в 2017 году**.

В качестве примера также можно привести развивающийся международный проект в сфере туризма «Один пояс, один путь», представляющий собой интеграцию стран Европы и Азии. Проект «Один пояс, один путь» вобрал в себя лучшие мировые культурные и туристические ресурсы, составляющие $80 \%$ Всемирного культурного наследия. Это самый динамичный и перспективный в мире Золотой туристский путь, затрагивающий более 60 стран, около 440 млн. людей. Согласно статистическим данным Государственного управления по делам туризма КНР, в период 13 пятилетки Китай в рамках проекта «Один пояс, один путь» осуществил 150 млн. рейсов китайских туристов в приграничные страны, потребление китайских туристов составило 200 млрд. долл. США; а также в Китай приехало 85 млн [11]. Как отмечает Линь Сюэ «в процессе планирования и разработки туристского продукта происходит подключение основных ценностей, национального духа и духа времени Китая [11].

Следовательно, способность специалистов, работающих в индустрии туризма к творческому мышлению, обнаруживать новые способы решения проблем, отказаться от существующих стереотипов в управлении является одним из основных конкурентных преимуществ страны, претендующей на высокий уровень конкурентоспособности на мировом туристском рынке.

\footnotetext{
* Как попсовая песня вдвое увеличила турпоток из Китая в Турцию. [Электронный ресурс], URL: https://www.tourprom.ru/news/40046/ (дата обращения 05.09.2018)

** Там же.
} 


\section{Библиографический список}

1. Азоев Г. Л. Конкурентные преимущества фирмы/ Г. Л. Азоев, А. П. Челенков. - М.: Новости, 2000. - 254 с.

2. Акулич О.В. Методологическая аргументация определения конкурентоспособности отрасли // Известия ИГЭА. 2011. № 3 (77) - с. 87-89.

3. Гилфорд Дж. Структурная модель интеллекта // Психология мышления. М., 1965. С. 433-456.

4. Коль О.Д. Экономический потенциал туристских предпринимательских структур крупного города: теория и методология оценки: Монография / Коль О. Д.-СПб., 2010.-95 с.

5. Ламбен, Жан-Жак. Стратегический маркетинг. Европейская перспектива / Ламбен, Жан-Жак. - Пер. с французского.-СПб.: Наука, 1996. - 589 с.

6. Морозова Н. С. Классификация конкурентных преимуществ в туризме. // Вестник Российского нового университета. М.: НОУ ВПО «Российский новый университет», 2011. -с. 45-49

7. Смит А. Исследование о природе и причинах богатства народов.- М., 1962.- С. 387-394

8. Старцев П.В. Анализ подходов к сущности понятий «конкурентоспособность предприятия» И «конкурентное преимущество» // Российское предпринимательство.- 2014.- Том 15.- № 16. - С. 4-15.

9. Фатхудинов Р.А. Конкурентоспособность организации в условиях кризиса: Экономика, маркетинг, менеджмент.-М.: Маркетинг,2002.-892 с.

10. В.Г. Федиов, В.В.Федиов. Предпринимательство: сфера сервиса: Учебное пособие.- М.: Издательскоторговая корпорация «Дашков и К», 2002.-210 с.

11. Линь Сюэ. Взаимосвязь стратегии «Один пояс, один путь» и сферы туризма. // Исследование развития экономики.-Цзилинь, 2016 г. - № 11 ч.2.- С.173-174 